\title{
Paediatric case of group A streptococcal pharyngitis, arthritis and osteomyelitis associated with dental neglect
}

\author{
Tomohiro Hiraoka $\odot{ }^{1},{ }^{1}$ Taro Chujo, ${ }^{2}$ Mitsuru Tsuge, ${ }^{3}$ Yoichi Kondo ${ }^{1}$
}

${ }^{1}$ Paediatrics, Matsuyama Red Cross Hospital, Matsuyama, Ehime, Japan

${ }^{2}$ Orthopaedics, Matsuyama Red Cross Hospital, Matsuyama, Ehime, Japan

${ }^{3}$ Department of Paediatrics, Okayama University Hospital, Okayama, Japan

\section{Correspondence to}

Dr Tomohiro Hiraoka;

tomohiro.hiraoka@gmail.com

Accepted 29 December 2020

\section{SUMMARY}

Group A streptococcus (GAS) causes a wide variety of infections in the paediatric population, ranging from pharyngitis to rare but severe invasive diseases, such as bacterial arthritis and osteomyelitis. Dental neglect is a type of child neglect in which caregivers fail to provide adequate care and treatment for dental diseases. This results in poor oral hygiene and can lead to complications including sepsis. We report the case of a 4-year-old boy, suffering from child neglect, presenting with GAS pharyngitis and subsequent bacterial arthritis in the right ankle, osteomyelitis in the right talus and abscess in the right calcaneus. He was first treated with penicillin, which was changed to clindamycin because of a suspected drug-induced rash. He was discharged after 6 weeks of intravenous therapy when symptoms had resolved and inflammatory markers were within the normal range. The case highlights that dental neglect may present a risk for subsequent invasive infections.

\section{BACKGROUND}

Group A streptococcus (GAS) is an aerobic, grampositive coccus, which causes pharyngitis, cutaneous infection and invasive infections (eg, bacteraemia, necrotising fasciitis, bacterial arthritis and osteomyelitis). Bacterial arthritis and osteomyelitis mostly result from haematogenous spread and rarely occur after GAS pharyngitis. ${ }^{1}$

Dental neglect is the failure of caregivers to provide adequate dental care typified by visibly

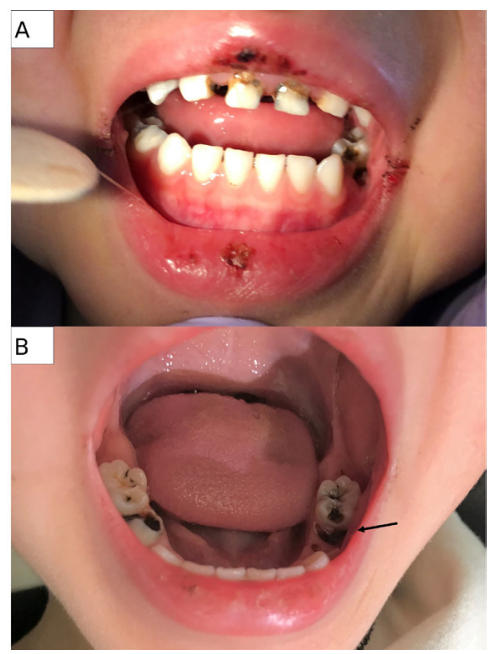

Figure 1 (A) Maxillary diastemata and periodontitis, and (B) severe caries.

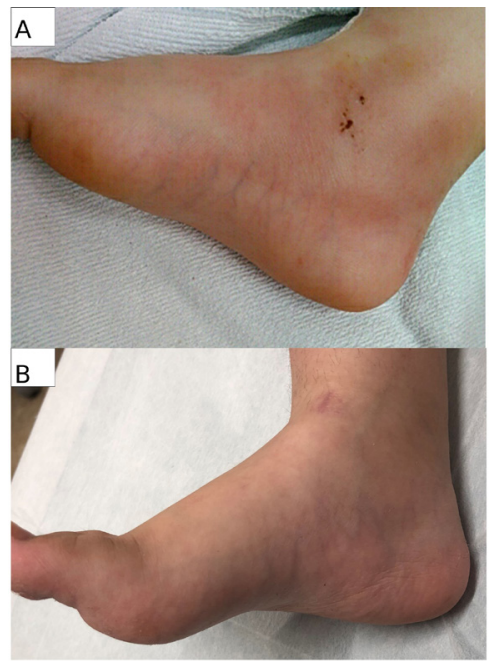

Figure 2 Right ankle (A) red and swollen on day 1, and (B) good therapeutic outcome.

untreated caries that are easily detected by nondental health professionals. ${ }^{2}$ Severe untreated caries and gingivitis can result in bacteraemia. ${ }^{3}$ We report a case of a 4-year-old boy suffering from dental neglect, who after acute pharyngitis, went on to develop GAS arthritis and osteomyelitis.

\section{CASE PRESENTATION}

A 4-year-old boy presented with sore throat, fever and pain in the right ankle for 3 days before consulting his family doctor. He was born healthy and had no significant medical history. His throat was red, and his right ankle was swollen and painful on examination. A throat rapid strep test was

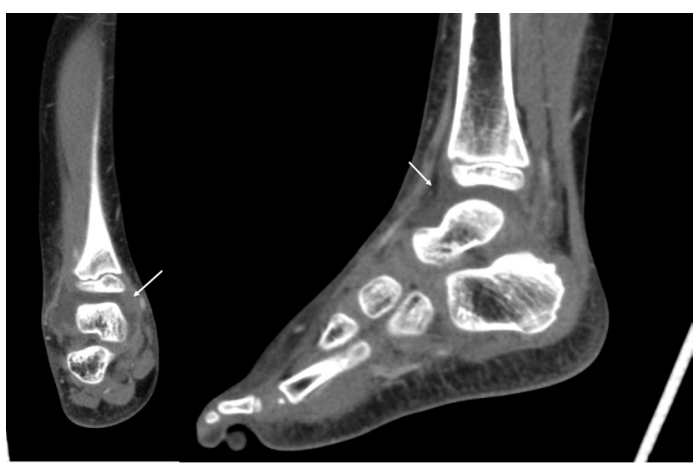

Figure 3 CT with contrast showing swelling and enhanced tissue around the right ankle and nonenhanced fluid retention in the ankle joint capsule. 


\begin{tabular}{|c|c|c|c|c|c|c|c|}
\hline Blood test & & & & & & Urinalysis & \\
\hline RBC & 4.03 & $\times 10^{12} / \mu \mathrm{L}$ & TP & 6.8 & $\mathrm{~g} / \mathrm{dL}$ & Specific gravity & 1.023 \\
\hline $\mathrm{Hb}$ & 113 & $\mathrm{~g} / \mathrm{L}$ & Alb & 3.2 & $\mathrm{~g} / \mathrm{dL}$ & Glucose & $(-)$ \\
\hline WBC & 27.14 & $\times 10^{9} / \mathrm{L}$ & T-Bil & 0.6 & $\mathrm{mg} / \mathrm{dL}$ & Bilirubin & $(-)$ \\
\hline Neutrophils & 90.0 & $\%$ & AST & 59 & U/L & Ketones & $(-)$ \\
\hline Lymphocytes & 7.0 & $\%$ & ALT & 31 & $\mathrm{U} / \mathrm{L}$ & Protein & $(1+)$ \\
\hline Platelets & 256 & $\times 10^{9} / \mathrm{L}$ & LDH & 420 & $\mathrm{U} / \mathrm{L}$ & Nitrites & $(-)$ \\
\hline PT-INR & 1.00 & & BUN & 7.3 & $\mathrm{mg} / \mathrm{dL}$ & Blood & $(-)$ \\
\hline APTT & 29.2 & $\mathrm{~s}$ & $\mathrm{Cr}$ & 0.33 & $\mathrm{mg} / \mathrm{dL}$ & Leucocyte esterase & $(-)$ \\
\hline Fibrinogen & 822.0 & $\mathrm{mg} / \mathrm{dL}$ & CK & 1562 & $\mathrm{U} / \mathrm{L}$ & & \\
\hline FDP & 11.1 & $\mu \mathrm{g} / \mathrm{mL}$ & CK-MB & 17 & $\mathrm{U} / \mathrm{L}$ & & \\
\hline D-dimer & 3.31 & $\mu \mathrm{g} / \mathrm{mL}$ & ASO & 1940 & $\mathrm{IU} / \mathrm{mL}$ & & \\
\hline CRP & 15.64 & $\mathrm{mg} / \mathrm{dL}$ & & & & & \\
\hline PCT & 8.33 & $\mathrm{ng} / \mathrm{mL}$ & & & & & \\
\hline
\end{tabular}

Alb, albumin; ALT, alanine aminotransferase; APTT, activated partial thromboplastin time; ASO, anti-streptolysin O; AST, aspartate aminotransferase; BUN, blood urea nitrogen; CK, creatine kinase; Cr, creatinine; CRP, C reactive protein; FDP, fibrinogen-degradation product; $\mathrm{Hb}$, haemoglobin; LDH, lactate dehydrogenase; PCT, procalcitonin; PT-INR, prothrombin time-international normalised ratio; RBC, red blood cell; T-Bil, total bilirubin; TP, total protein; WBC, white blood cell.

positive. A radiograph showed no fracture or dislocation. Since a dose of ceftriaxone (CTRX) did not alleviate the pain, he was referred to our hospital.

His family had previously been in contact with us for child neglect. A thorough physical examination was conducted. The patient weighed $17.1 \mathrm{~kg}(+0.1 \mathrm{SD})$, was $101.9 \mathrm{~cm}(-0.6 \mathrm{SD})$ tall and had a temperature of $38.4^{\circ} \mathrm{C}$. Dry lips and an inflamed throat were observed, and gingivitis and many mild-to-severe carious lesions were clearly noticeable (figure 1). The right ankle was swollen and painful, which precluded walking (figure 2A). Heart and lung sounds were normal.

\section{INVESTIGATIONS}

A blood test showed that white blood cell, $\mathrm{C}$ reactive protein (CRP) and procalcitonin (PCT) levels were increased to $27.14 \times 10^{9} / \mathrm{L}, 15.64 \mathrm{mg} / \mathrm{dL}$ and $8.33 \mathrm{ng} / \mathrm{mL}$, respectively; and anti-streptolysin O (ASO) activity was as high as $1940 \mathrm{IU} / \mathrm{mL}$ (table 1). An enhanced CT revealed arthritis in the right ankle (figure 3). White pus, obtained by puncture from the right lateral malleolus, demonstrated gram-positive chain-forming cocci, suggestive of GAS (figure 4). Whole-body non-enhanced CT showed no other signs of arthritis, acute otitis media or retropharyngeal abscess.

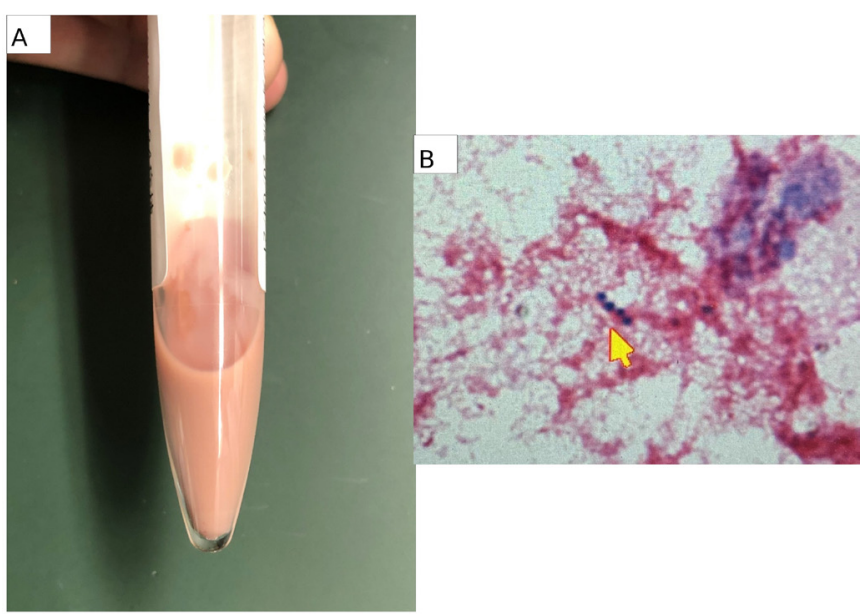

Figure 4 (A) Purulent fluid punctured from the right ankle; (B) grampositive, chain-forming coccus.

\section{TREATMENT}

The patient was admitted with a temporary designated guardian. On day 1, arthroscopic synovectomy and joint cleaning were performed, and a drainage tube was inserted. A course of sulbactam/ampicillin was initiated but changed to ampicillin (ABPC) and clindamycin (CLDM) to maximise the dosage of ABPC. Daily dental brushing was performed by a child guardian or nurse. Throat and blood cultures were negative, but the punctured fluid culture revealed GAS that was sensitive to ABPC and CLDM. ABPC alone was continued from day 3. Fever disappeared from day 5, and the right ankle swelling and redness improved (figure 2B). The drainage tube was removed on day 7, and rehabilitation was started. Gadolinium-enhanced MRI on day 8 (figure 5A) revealed osteomyelitis in the right talus and an abscess in the right calcaneus. Administration of antibiotics

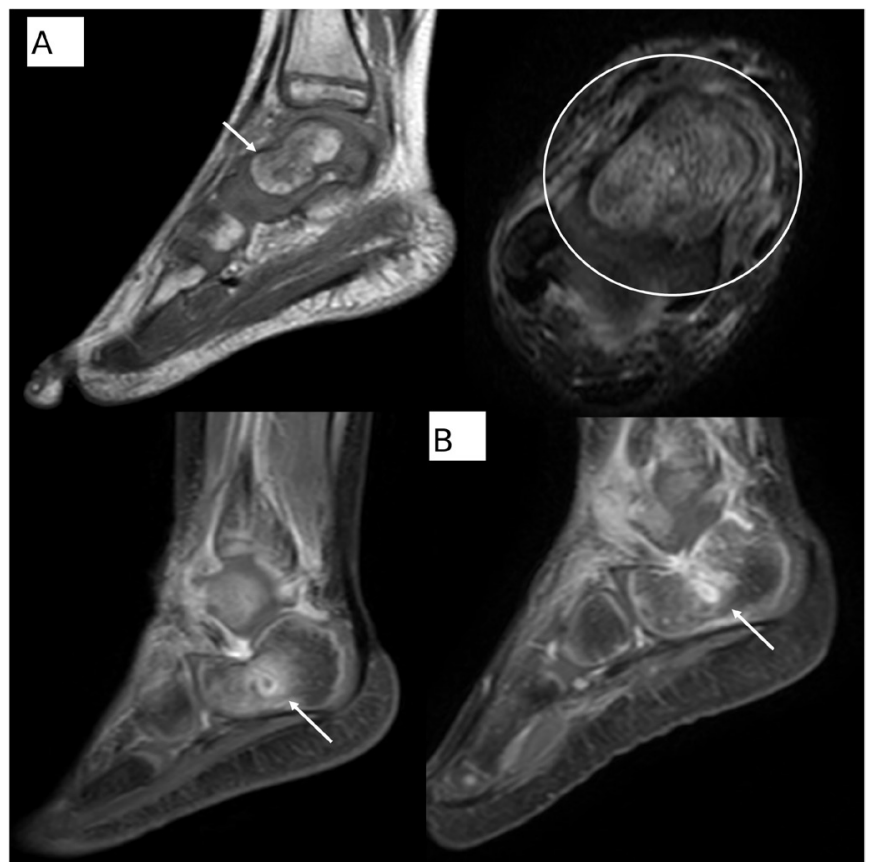

Figure 5 (A) MRI on day 8: low signal at T1 weighted image (WI) (upper left) and high signal at T2WI (upper right) showing osteomyelitis at the right talus, and enhanced T1WI (lower left) showing an abscess at the right calcaneus; (B) decrease in the abscess size on day 30 . 
was continued and surgical intervention was not required: the abscess was small in size and showed improvement with the antibiotic treatment. On day 18, pink, raised and non-circular rashes developed on both feet and ears, and expanded symmetrically to the whole body. Due to a suspected allergic reaction to ABPC, ABPC was switched to CLDM and chlorpheniramine on day 21, and the rashes disappeared on day 28.

Immunological screening was normal. The drug-induced lymphocyte stimulation test to ABPC was negative. The $\mathrm{emm}$ gene-type GAS was determined by the National Institute of Infectious Diseases in Japan to be emm 1 , producing the M-1 protein. Intravenous antibiotics were administered for 6 weeks until CRP and PCT were within the normal range. The patient was then discharged and advised oral amoxicillin for another 6 weeks.

\section{OUTCOME AND FOLLOW-UP}

At 2 months after discharge, the patient had completed oral medication and had good motor function.

\section{DISCUSSION}

GAS causes a wide variety of infections in the paediatric population, ranging from pharyngitis to severe invasive diseases. Over 600 million cases of GAS pharyngitis occur per year. ${ }^{4}$ Invasive cases are reported in 1.5-3.8/100 000 people, $14.8 \%$ of which are bacterial arthritis and osteomyelitis. ${ }^{5}$ GAS accounts for $8 \%$ and $4 \%$ of cases in children with bacterial arthritis and osteomyelitis, respectively. ${ }^{78}$ The risk factors for bacterial arthritis and osteomyelitis in older infants and children include immunodeficiency, trauma, vascular catheters and varicella zoster virus infection. No such factor was found in the patient's history and examination, except for minor scratches on the right ankle.

GAS enters the joint space mostly through haematogenous spread. One major virulence factor allowing invasiveness is the $\mathrm{M}$ protein, encoded by the emm gene. It provides anti-phagocytic properties, which help GAS avoid destruction by the host's immune system. The type of $\mathrm{M}$ protein closely correlates with specific clinical phenotypes, for example, M-1, 3, 5, 6, 12, 14, 17,19 and 24 with pharyngitis, and M-33, 41, 42, 52, 53 and 70 with impetigo. ${ }^{9}$ There is also a definitive and consistent tendency for the M-1 strain to be associated with more life-threatening infections because it adheres to the cell membrane more strongly and penetrates the mucosa more efficiently. ${ }^{4}$ However, bacteraemia rarely follows streptococcal pharyngitis since the host's immune system efficiently eliminates GAS. ${ }^{1}$ In this case, an additional contributory factor in disease dissemination could be poor oral hygiene. Severe untreated caries and gingivitis are risk factors for bacteraemia. ${ }^{3}$ Dental or periodontal procedures and diseases function as an entry portal for oral bacteria. A case of M-1 GAS brain abscess after milk tooth extraction has been previously reported. ${ }^{10}$ Our patient suffered from chronic severe caries and gingivitis associated with dental neglect. A positive rapid strep test and elevation of ASO on admission suggested streptococcal pharyngitis. The M-1 strain of GAS from initial pharyngitis is likely to have spread haematogenously due to poor oral hygiene resulting in the subsequent invasive infection. Negative throat and blood cultures could have resulted from the timing of collecting cultures after the CTRX injection and the low yield of positive blood culture. ${ }^{8}$

Bacterial arthritis and osteomyelitis are rare but can result from invasive types of GAS infections. More careful follow-up is required for patients with GAS pharyngitis, especially those with poor oral hygiene, as this may provide an entry point for haematogenous spread of infection.

\section{Learning points}

- This is a rare case of streptococcal arthritis and osteomyelitis following pharyngitis. The patient had no significant risk factors in the medical history but suffered from dental neglect.

- Dental or periodontal procedures and diseases can function as an entry point for oral bacteria into the bloodstream.

- Poor oral hygiene associated with dental neglect may be a contributory factor for invasive infection after group $A$ streptococcus (GAS) pharyngitis.

- Careful follow-up is recommended for patients with GAS pharyngitis suffering from dental neglect.

Acknowledgements The authors would like to thank Editage (www.editage. com) for English language editing. They also wish to acknowledge Dr Nagaaki Terakado from the Department of Dental Surgery at Matsuyama Red Cross Hospital, for his help in collecting images, and Dr Tadayoshi Ikebe from the Department of Bacteriology 1, at The National Institute of Infectious Diseases, Japan, for his help in analysis of bacterial strains.

Contributors TH wrote the manuscript. TC was involved in managing the patient. MT and YK supervised and approved the manuscript.

Funding The authors have not declared a specific grant for this research from any funding agency in the public, commercial or not-for-profit sectors.

Competing interests None declared.

Patient consent for publication Obtained.

Provenance and peer review Not commissioned; externally peer reviewed.

ORCID iD

Tomohiro Hiraoka http://orcid.org/0000-0002-6670-9069

\section{REFERENCES}

1 Stevens DL, Bryant AE. Severe Group A Streptococcal Infections. In: Ferretti JJ, Stevens DL, Fischetti VA, eds. Streptococcus pyogenes: basic biology to clinical manifestations [Internet]. Oklahoma City: University of Oklahoma Health Sciences Center, 2016.

2 Ramazani N. Child dental neglect: a short review. Int J High Risk Behav Addict 2014;3:e21861.

3 Brennan MT, Kent ML, Fox PC, et al. The impact of oral disease and nonsurgical treatment on bacteremia in children. J Am Dent Assoc 2007;138:80-5.

4 Walker MJ, Barnett TC, McArthur JD, et al. Disease manifestations and pathogenic mechanisms of group A Streptococcus. Clin Microbiol Rev 2014;27:264-301.

5 Waddington CS, Snelling TL, Carapetis JR. Management of invasive group A streptococcal infections. J Infect 2014;69:S63-9.

6 Nelson GE, Pondo T, Toews K-A, et al. Epidemiology of invasive group A streptococcal infections in the United States, 2005-2012. Clin Infect Dis 2016;63:478-86.

7 Ferroni A, Al Khoury H, Dana C, et al. Prospective survey of acute osteoarticular infections in a French paediatric orthopedic surgery unit. Clin Microbiol Infect 2013;19:822-8.

8 Dartnell J, Ramachandran M, Katchburian M. Haematogenous acute and subacute paediatric osteomyelitis. J Bone Joint Surg Br 2012;94-B:584-95.

9 Metzgar D, Zampolli A. The M protein of group A Streptococcus is a key virulence factor and a clinically relevant strain identification marker. Virulence 2011;2:402-12.

10 Hayashi A, Takano T, Suzuki A, et al. Group A streptococcal brain abscess: a case report and a review of the literature since 1988. Scand J Infect Dis 2011:43:553-5. 
Copyright 2021 BMJ Publishing Group. All rights reserved. For permission to reuse any of this content visit https://www.bmj.com/company/products-services/rights-and-licensing/permissions/

BMJ Case Report Fellows may re-use this article for personal use and teaching without any further permission.

Become a Fellow of BMJ Case Reports today and you can:

- Submit as many cases as you like

- Enjoy fast sympathetic peer review and rapid publication of accepted articles

Access all the published articles

Re-use any of the published material for personal use and teaching without further permission

Customer Service

If you have any further queries about your subscription, please contact our customer services team on +44 (0) 2071111105 or via email at support@bmj.com.

Visit casereports.bmj.com for more articles like this and to become a Fellow 